\title{
The effect on the virulence and infectivity of Salmonella typhimurium and Salmonella gallinarum of acquiring antibiotic resistance plasmids from organisms that had caused serious outbreaks of disease
}

\author{
By H. WILLIAMS SMITH AND J. F. TUCKER \\ Houghton Poultry Research Station, Houghton, Huntingdon \\ Cambs. PE17 2DA
}

(Received 7 November 1978)

\section{SUMMARY}

Antibiotic resistance plasmids from organisms that had caused serious epidemics, including those responsible for epidemics of chloramphenicol-resistant typhoid fever and dysentery in Central America, were transferred to a strain of Salmonella typhimurium and of Salmonella gallinarum. The virulence and infectivity of these $\mathrm{R}^{+}$forms were then compared with the $\mathrm{R}^{-}$parent forms in orally inoculated chickens.

None of the $\mathrm{R}^{+}$forms were more virulent than their $\mathrm{R}^{-}$parent forms. The mortality rates they produced were either the same as or less than that of their $\mathrm{R}$ - parent forms. The mortality rates were not increased by feeding the chickens on diets containing antibiotics against which the plasmids provided resistance.

The removal of the plasmids from some $R^{+}$forms of decreased virulence was not accompanied by any alteration in virulence, indicating that they were less virulent mutants of the parent strain that had conjugated preferentially. In other cases their virulence was increased, indicating that the very possession of the plasmid was involved in their decreased virulence. Of four forms of the S. gallinarum strain harbouring the plasmid that had been incriminated in the Central American dysentery outbreak, one was as virulent as the parent $R-$ form and the other three were less virulent. Preferential conjugation by an avirulent mutant was responsible for the lack of virulence of one of them but the very possession of the plasmid appeared responsible for the decreased virulence of the other two. The decreased virulence of de-repressed $\mathrm{F}^{+}$and $\mathrm{I}^{+}$forms of the $S$. typhimurium strain was increased to that of repressed $\mathrm{F}^{+}$form and of the parent form by plasmid removal.

Organisms of the $\mathrm{R}^{+}$forms of the $S$. typhimurium strain were not excreted in larger amounts or for longer periods of time by infected chickens than organisms of the $\mathbf{R}^{-}$parent form were. Neither did organisms of the $\mathbf{R}^{+}$forms of this strain or the $S$. gallinarum strain spread more rapidly or more extensively from infected chickens to in-contact chickens than organisms of the $\mathrm{R}^{-}$parent forms did. When antibiotics against which the infecting $\mathbf{R}^{+}$organisms provided resistance were included in the diet of these chickens the $R^{+}$organisms were usually excreted 
in greater amounts, for longer periods of time and spread more rapidly and more extensively from the infected chickens to the in-contact chickens.

\section{INTRODUCTION}

When antibiotic resistance plasmids have been transferred to strains of Salmonella typhimurium the resulting $\mathrm{R}^{+}$forms have either had the same degree of virulence as their parent strain or a lower degree of virulence (Watanabe \& Watanabe, 1969; Thiele, 1970; Watanabe, 1971; Smith, 1972; Watanabe, 1976). Those of reduced virulence are probably derived from lowly virulent mutants of the parent strain that conjugated preferentially with the plasmid donor organisms (Smith, 1972; Watanabe, 1976). There is also evidence that the very presence of a plasmid might be responsible for the small reduction in virulence exhibited by some $R^{+}$forms (Smith, 1972). Because there have been particularly serious epidemics caused by $\mathrm{R}^{+}$salmonellas and shigellas, it seemed worth while reinvestigating the association between the $R^{+}$state and virulence using plasmids from organisms causing some of these epidemics; the results are reported in this paper. The plasmids were transferred to the same $S$. typhimurium strain and the virulence of the resulting $\mathrm{R}^{+}$forms assessed by oral inoculation of 1-day-old chickens. S. typhimurium infections are highly lethal to chickens of this age but not to older chickens; the latter, however, usually excrete the organisms in their faeces for several weeks after inoculation. The effects of some of the plasmids were also studied in a Salmonella gallinarum strain, because organisms of this serotype produce a generalized infection in chickens of all ages resembling $S$. typhi infection in human beings (Smith, 1955); unlike $S$. typhimurium, the organisms do not colonize the alimentary tract. The effect of the plasmids on the infectivity of the host organism was studied by inoculating only a small proportion of the chickens in each of several groups with a different $R^{+}$form of the $S$. typhimurium or $S$. gallinarum strain and then monitoring the rate at which the infection spread to the remainder of the chickens in each group. Because preventive medication is often resorted to in some outbreaks of disease, antibiotics were given to some of the groups to see whether this influenced the spread of infection.

\section{MATERIALS AND METHODS}

\section{Bacteria and plasmids}

All the plasmids were maintained in their original bacterial hosts and in organisms to which they were transferred on Dorset's egg medium at $5^{\circ} \mathrm{C}$. Plasmids R1, R2, R3 and R4 were from outbreaks of Salmonella typhi infection in Mexico (Datta \& Olarte, 1974), India (Paniker \& Vimala, 1972), Vietnam (Butler et al. 1973) and Thailand (Lampe, Mansuwan \& Duangmani, 1974) respectively. Plasmid R5 was from an outbreak of Shigella dysenteriae infection in Central America (Datta \& Olarte, 1974), plasmid R6 was from an outbreak of Shigella flexneri infection in Japan (Mitsuhashi, 1971), plasmids R7 and R8 were from outbreaks of Salmonella typhimurium infection in children in South American. 
hospitals (Peluffo, Irino \& Mello, 1974) and R9 was from an outbreak of Salmonella typhimurium infection in calves in England (Anderson, 1968). The outbreaks in which plasmids R1, R5, R6, R7, R8 and R9 had been involved were all severe and/or widespread; plasmids R2, R3 and R4 were included in the investigation because they resembled plasmid $\mathrm{R} 1$ in belonging to compatibility group $\mathrm{H} 1$ (Anderson, 1975) and in being temperature-sensitive (Smith, 1974). Plasmids R1 to $\mathbf{R} 6$ provided resistance to chloramphenicol, tetracycline, streptomycin, spectinomycin and sulphonamides, plasmid R7 to ampicillin, streptomycin and sulphonamides, plasmid R8 to chloramphenicol, tetracyclines and neomycin and plasmid R9 to ampicillin, tetracycline, streptomycin and sulphonamides. The other plasmids studied, repressed F and de-repressed F and I (Idrd 16) (Hardy et al. 1973), included to elucidate the effects of plasmid carriage on virulence, were linked to tetracycline resistance determinants. Their repressed and derepressed status was confirmed, when necessary, by assessing their susceptibility to visual lysis on nutrient agar by the MS2 (Davis, Strauss \& Sinsheimer, 1961) and IfI (Meynell \& Lawn, 1968) phages.

The two salmonella strains in which all the plasmids were implanted were a nalidixic acid-resistant $\left(\right.$ nal $\left.^{r}\right)$ mutant of an $S$. typhimurium strain of phage type 14, strain $T$, and a nalr $S$. gallinarum strain, strain $G$; both had been isolated initially from diseased chickens and neither of them possessed conjugative plasmids as judged by their failure to mobilize antibiotic resistance determinants in $E$. coli K12.

The preparation of $R^{+}$forms of the $\mathrm{S}$. typhimurium and $\mathrm{S}$. gallinarum strains

Each plasmid donor strain and the nalr $S$. typhimurium $\mathbf{T}$ strain or the S. gallinarum $\mathrm{G}$ strain were grown together for $24 \mathrm{~h}$ at $37^{\circ} \mathrm{C}$, or at $28^{\circ} \mathrm{C}$ when the thermo-sensitive plasmids R1 to R4 were transferred. Organisms of the $T$ and $G$ strains that had acquired the plasmids were selected by plating the mixed cultures on MacConkey's agar containing $20 \mu \mathrm{g}$ per ml each of sodium nalidixate and of one of the antibiotics against which the particular plasmid provided resistance. The proportion of organisms that had acquired the plasmid was estimated, when necessary, from colony counts of the mixed culture (Miles, Misra \& Irwin, 1938) on MacConkey's agar containing sodium nalidixate alone and with an antibiotic against which the plasmid provided resistance. Only those $\mathbf{R}^{+}$forms that, like the $\mathrm{T}$ and $\mathrm{G}$ parent forms, (1) possessed the typical colonial morphology associated with smoothness, (2) were not agglutinated in slide tests by $0.2 \%$ acriflavine solution and (3) were not lysed in plate tests by the anti-rough phage $65 \mathrm{R}$ (Kay, 1962) were retained.

\section{Removal of plasmids}

Plasmids were removed from $\mathrm{R}^{+}$forms by treatment with $10 \%$ sodium lauryl sulphate (Tomoeda et al. 1968) or by serial passage in nutrient broth at $44^{\circ} \mathrm{C}$.

\section{Experimental animals}

Chickens, whose sex was not determined, were from salmonella-free Light Sussex, Rhode Island Red or White Leghorn flocks maintained at this station. 
They were kept under good hygienic conditions in groups of 30-40 on wire-mesh floors in identically constructed pens in an animal house maintained at $21^{\circ} \mathrm{C}$; additional heating was provided, when necessary, by suspending an infra-red brooding lamp over each pen. They were fed ad libitum on a diet of the following composition: wheat meal, $40 \%$; maize meal, $40 \%$; British white-fish meal, $20 \%$; mineral and vitamin supplement, $0 \cdot 25 \%$. When required, antibiotics, as premixes, were incorporated in the food by means of a mechanical mixer.

\section{Virulence tests}

Groups of 30-40 Light Sussex chickens in their first day of life, and before they were provided with food and water, were given $0.3 \mathrm{ml}$ of a shaken broth culture that had been incubated at $37^{\circ} \mathrm{C}$ for $24 \mathrm{~h}$ of the $S$. typhimurium $\mathrm{T}$ strain or of one or other of a set of different $R^{+}$forms of it. This represented a dose of $5.0 \times 10^{8}$ viable organisms; it was placed directly in the crop by means of a Pasteur pipette. Because batches of chickens may vary in their susceptibility to infection, each complete experiment was performed on the same batch. When large groups were necessary, the entire experiment was replicated in further batches. The livers of all chickens were examined bacteriologically to confirm that they had died from $S$. typhimurium infection and that the organisms had not lost their antibiotic-resistance plasmids. Virulence tests on the $\mathrm{R}^{+}$forms of the $S$. gallinarum $G$ strain were performed in the same manner as those on the S.typhimurium $\mathrm{R}^{+}$ forms except that 4-week-old White Leghorn or Rhode Island Red chickens were used. These two breeds were chosen because they differed greatly in their susceptibility to lethal infection.

\section{Tests for duration of faecal excretion and for infectivity}

For assessing the duration of faecal excretion of $S$. typhimurium organisms groups of 30-40 chickens were inoculated in the usual manner with the $T$ strain or with different $R^{+}$forms of it when they were 4 days old; unlike those infected during the first day of life, chickens infected at this age do not usually become unwell. At intervals afterwards, faecal swabs were taken from the cloaca of the chickens and inoculated in a standard manner onto half of the surface of plates of brilliant green agar (Oxoid CM263) containing $20 \mu \mathrm{g} / \mathrm{ml}$ of sodium nalidixate and $1 \mu \mathrm{g} / \mathrm{ml}$ of novobiocin; very few faecal bacteria grow on this medium and the colonies of those that do can easily be differentiated visually from those of salmonellas. After incubation at $37^{\circ} \mathrm{C}$ for $24 \mathrm{~h}$ the amount of salmonella growth on the plates was recorded according to the following notation: $++++=$ confluent; $+++=$ almost confluent; $++=$ partly confluent; $+=$ numerous mainly discrete colonies; $\pm=$ numerous discrete colonies; $50=$ approximately 50 colonies; $5=$ approximately 5 colonies; $1=$ approximately 1 colony. Plates inoculated with faeces from chickens infected with $\mathrm{R}^{+}$organisms had an appropriate antibiotic-containing disk applied to their surface to determine whether a significant proportion of the salmonella organisms that grew on them had lost their plasmids. After being used for inoculating the brilliant green agar plates, 
the faecal swabs were incubated in selenite broth at $37^{\circ} \mathrm{C}$ for $24 \mathrm{~h}$ and then subcultured on brilliant green agar.

Infectivity studies were performed in the manner described above except that only five chickens in each group were experimentally infected when they were 4 days old. The faeces of all the chickens were examined at frequent intervals afterwards so that the rate at which the infection spread from these five to the remainder of the chickens in the same group could be assessed. Because $S$. gallinarum is lethal for chickens of all ages and does not colonize the alimentary tract, the mortality rate was used to assess the rate of spread of this organism throughout the groups of in-contact chickens. In addition, blood samples from the surviving chickens were examined for agglutinins to $S$. gallinarum by means of a plate agglutination test.

\section{RESULTS}

The mortality rate in chickens inoculated with different $R^{+}$forms of Salmonella typhimurium or Salmonella gallinarum

The mortality rate in groups of 150 1-day-old chickens inoculated with an $\mathrm{R} 1^{+}, \mathrm{R2}^{+}, \mathrm{R3}^{+}, \mathrm{R4}^{+}, \mathrm{R5}^{+}, \mathbf{R} 6^{+}, \mathbf{R 7}{ }^{+}$or an $\mathbf{R} 9^{+}$form of the S. typhimurium $\mathbf{T}$ strain was $75,80,69,73,41,55,88$ and $46 \%$ respectively. That for two groups given the $R^{-} \mathrm{T}$ strain was 88 and $86 \%$. The virulence of other isolates of $\mathrm{R} 1^{+}$, $\mathrm{R}^{+}, \mathrm{R}^{+}$and $\mathrm{R}^{+}$forms that had been obtained from matings in which at least $10 \%$ of the $\mathrm{T}$ organisms in the mixed cultures were known to have acquired the $R$ plasmid of the donor were tested in groups of 25-95 chickens; neither were any more virulent than the $\mathrm{R}^{-}$parent strain.

As in the S.typhimurium experiments, none of the $\mathrm{R}^{+}$forms of the S. gallinarum $\mathrm{G}$ strain were more virulent than the $\mathrm{R}^{-}$parent form. The mortality rate in groups of 116 White Leghorn chickens inoculated with the $\mathbf{R} 1^{+}, \mathbf{R 6} 6^{+}, \mathbf{R} 7^{+}, \mathbf{R} 8^{+}$and $\mathbf{R} 9^{+}$ forms and the $\mathrm{R}^{-}$parent form, the only forms tested, was $25,28,22,6,3$ and $33 \%$ respectively. The corresponding figures in a similar experiment using chickens of the more susceptible Rhode Island Red breed was 81, 87, 75, 20, 27 and $87 \%$ respectively. Another $\mathrm{R1}^{+}$form, an $\mathrm{R2}^{+}$, an $\mathrm{R3}^{+}$, an $\mathrm{R4}^{+}$and an $\mathrm{R6}^{+}$form of the $G$ strain and forms possessing the plasmids of other $S$. typhi strains isolated from the outbreaks of disease in which the R3 and R4 plasmids had been incriminated were tested in groups of 25-95 chickens; none of them were more virulent than the $\mathrm{R}^{-}$parent form. Four $\mathrm{R}^{+}$forms originating from separate matings were each tested in a group of 60 Rhode Island Red chickens. In one group the mortality rate, $97 \%$, was as high as in a group given the $\mathbf{R}^{-}$parent form and in another two it was $5 \%$ and $37 \%$, all the organisms isolated from the livers of the chickens that died in the latter group having lost their plasmids; in the fourth group no deaths occurred.

In additional experiments, groups of 35-50 chickens inoculated with the R5+ or R7+ forms of the S. typhimurium $\mathrm{T}$ strain or the R7+ form of the $S$. gallinarum $G$ strain were fed throughout on diets containing 20,100 and $500 \mathrm{mg} / \mathrm{kg}$ of an antibiotic against which their plasmids provided resistance, chloramphenicol, 


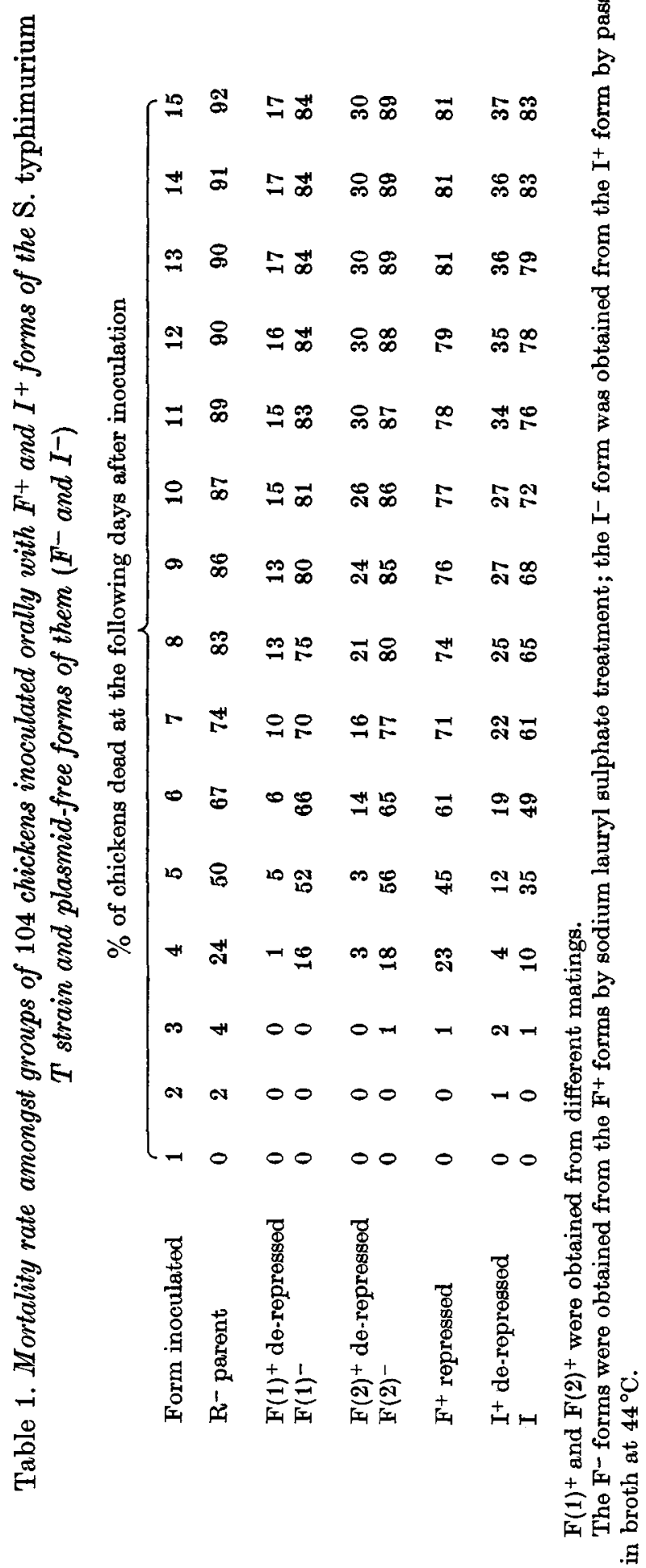


Virulence and infectivity of salmonellas

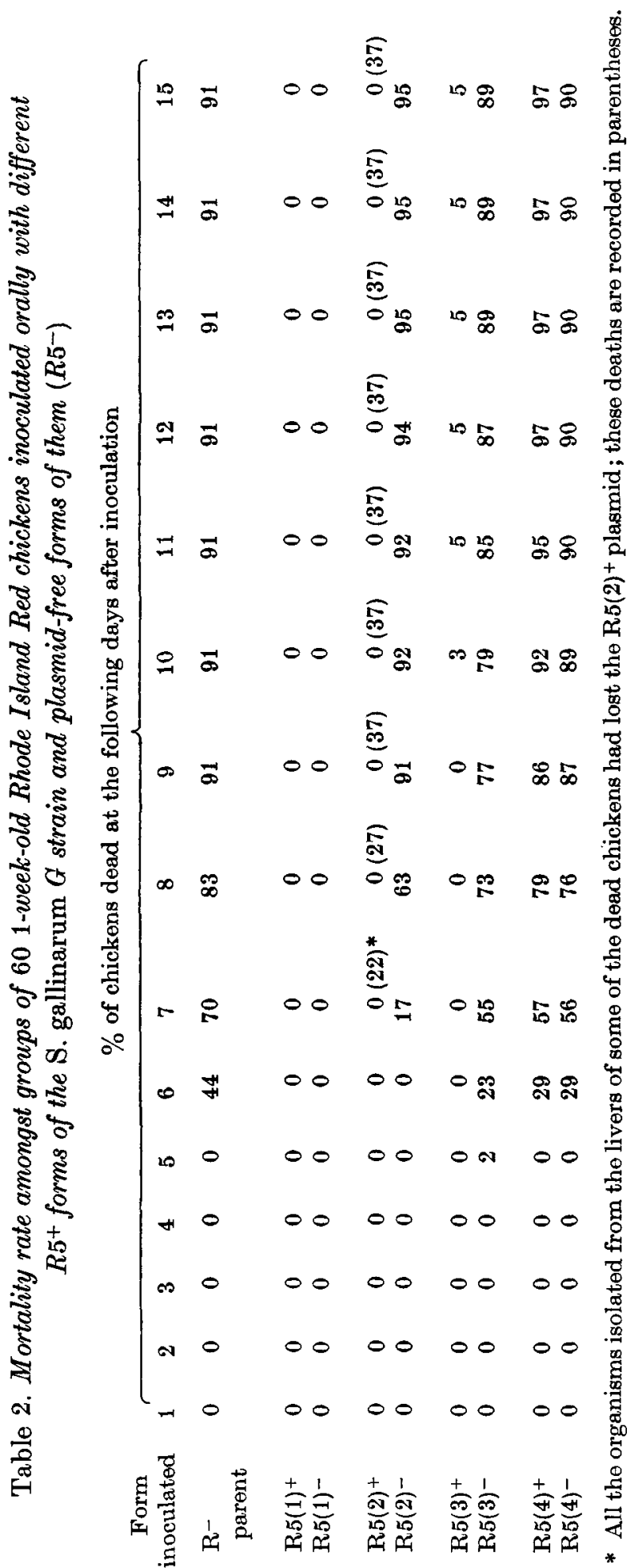


tetracyclines and streptomycin in the case of chickens inoculated with the $\mathrm{R5}^{+}$ form and ampicillin in the case of those inoculated with the R7+ form; the mortality rate in these groups was no higher than in corresponding groups inoculated with the relevant $R^{+}$organisms but fed on a non-medicated diet.

\section{The effect of plasmid loss on virulence}

The virulence of plasmid-free forms, obtained by sodium lauryl sulphate treatment, from the $\mathrm{R5}^{+}$and $\mathrm{R6}^{+}$forms of the $S$. typhimurium $\mathrm{T}$ strain and from the $\mathrm{R}^{+}$form of the $S$. gallinarum $\mathrm{G}$ strain differed little from that of the $\mathbf{R}^{+}$ forms from which they were derived. In experiments employing groups of 70-150 chickens the mortality rate caused by the $\mathrm{R5}^{+}, \mathrm{R} 5^{-}, \mathrm{R} 6^{+}$and $\mathrm{R} 6^{-}$forms of the $\mathrm{T}$ (strain was $41,44,54$ and $63 \%$ respectively and that caused by the $\mathrm{R}^{+}$and $\mathrm{R}^{-}$- forms of the $\mathrm{G}$ strain was 0 and $1 \%$ respectively; the mortality rate in the groups given the $\mathrm{R}-\mathrm{T}$ and $\mathrm{G}$ strains was 86 and $33 \%$ respectively. Increased virulence, however, did accompany plasmid loss from de-repressed $\mathrm{F}^{+}$and $\mathrm{I}^{+}$ forms of the $\mathrm{T}$ strain and from two of the four $\mathrm{R5^{+ }}$ forms of the $\mathrm{G}$ strain; the results of these experiments are illustrated in Tables 1 and 2. Table 1 also shows that whereas the mortality rate in the groups given the de-repressed $\mathrm{F}^{+}$and $\mathrm{I}^{+}$ forms was much lower than that given the $R^{-}$parent form, the mortality rate in the group given the repressed $\mathrm{F}^{+}$form was similar to that in the group given the $\mathrm{R}^{-}$parent form. In $24 \mathrm{~h}$ matings, all four $\mathrm{R} 5^{+}$forms of the $\mathrm{G}$ strain transferred their plasmids at the same rate to $E$. coli $\mathrm{K} 12$, approximately $10 \%$ of the $\mathrm{K} 12$ organisms acquiring the plasmids. One, in which plasmid loss was accompanied by increased virulence (no. 3 in Table 2), was examined by Dr A. M. Lawn in the electron microscope. He reported that no organisms possessing sex pili were seen, which infers that the plasmid in this form was not de-repressed.

\section{The duration and spread of infection in chickens inoculated with different $R^{+}$forms of the $\mathrm{S}$. typhimurium and $\mathrm{S}$. gallinarum strains}

Groups of 33 four-day-old chickens were inoculated orally with organisms of the $\mathrm{R} 1^{+}, \mathrm{R} 5^{+}, \mathrm{R} 6^{+}, \mathrm{R} 7^{+}$and $\mathrm{R} 9^{+}$forms of the $S$. typhimurium $\mathrm{T}$ strain and their faeces were examined at weekly intervals for 51 days. None of the groups excreted the organisms in their faeces in larger amounts or for longer periods of time than a group inoculated with organisms of the $\mathrm{R}^{-}$parent form. In a similar experiment but in which only five chickens in each group were inoculated, none of the $\mathrm{R}^{+}$ forms spread more rapidly or extensively to the other chickens in the groups than did the $\mathrm{R}^{-}$parent form and the infections that developed did not persist longer in the $\mathrm{R}^{+}$groups than in the $\mathrm{R}^{-}$group. However, when this experiment was repeated using chickens fed on diets containing antibiotics to which the organisms of the $\mathrm{R}^{+}$form of the $\mathrm{T}$ strain to which they were exposed were resistant, these organisms usually spread more rapidly and more extensively in the antibiotic-fed groups than in the groups fed on the ordinary diet, and the infections that developed in the antibiotic-fed groups were usually heavier and persisted for longer periods of time. This was particularly noticeable in groups fed on diets containing spectinomycin or ampicillin $(100 \mathrm{mg} / \mathrm{kg})$ and less so in those fed on 


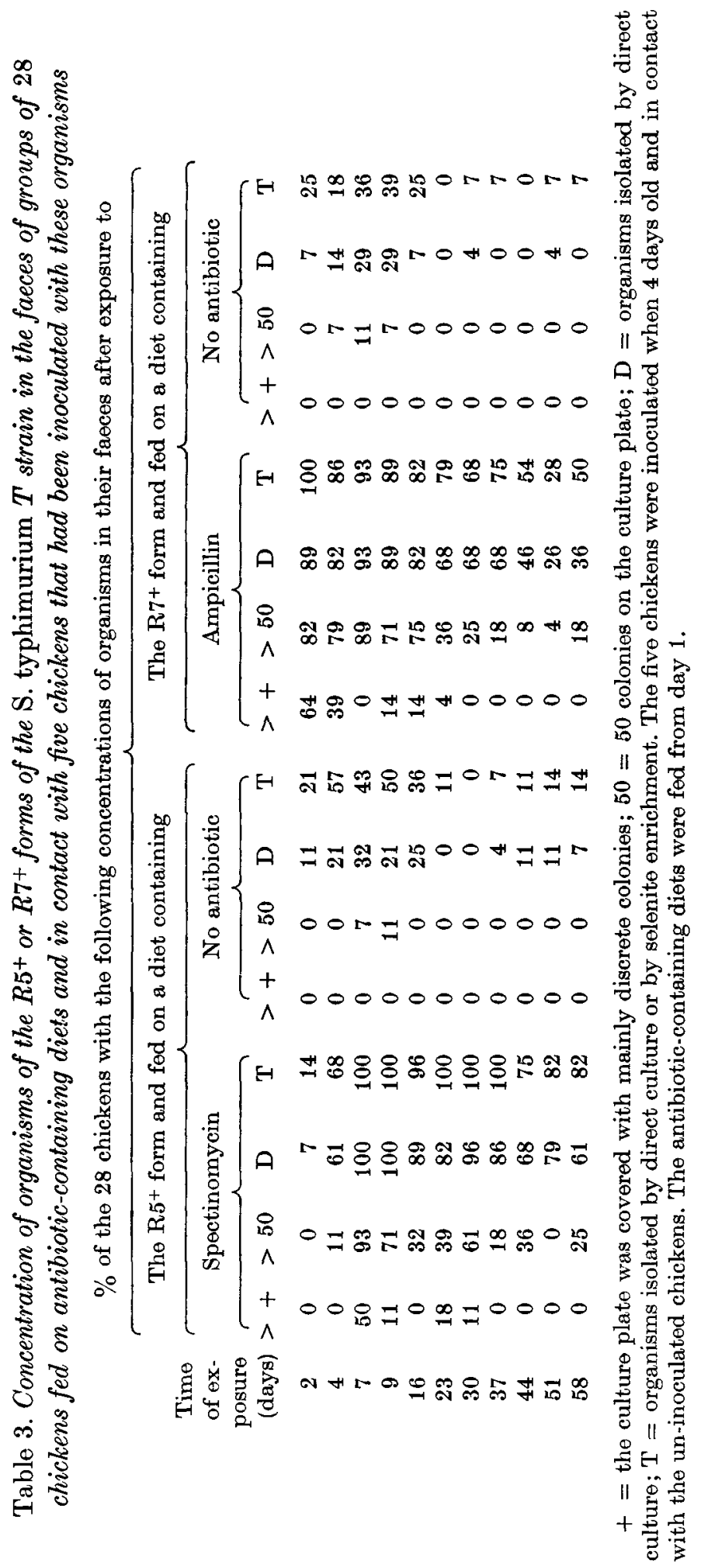




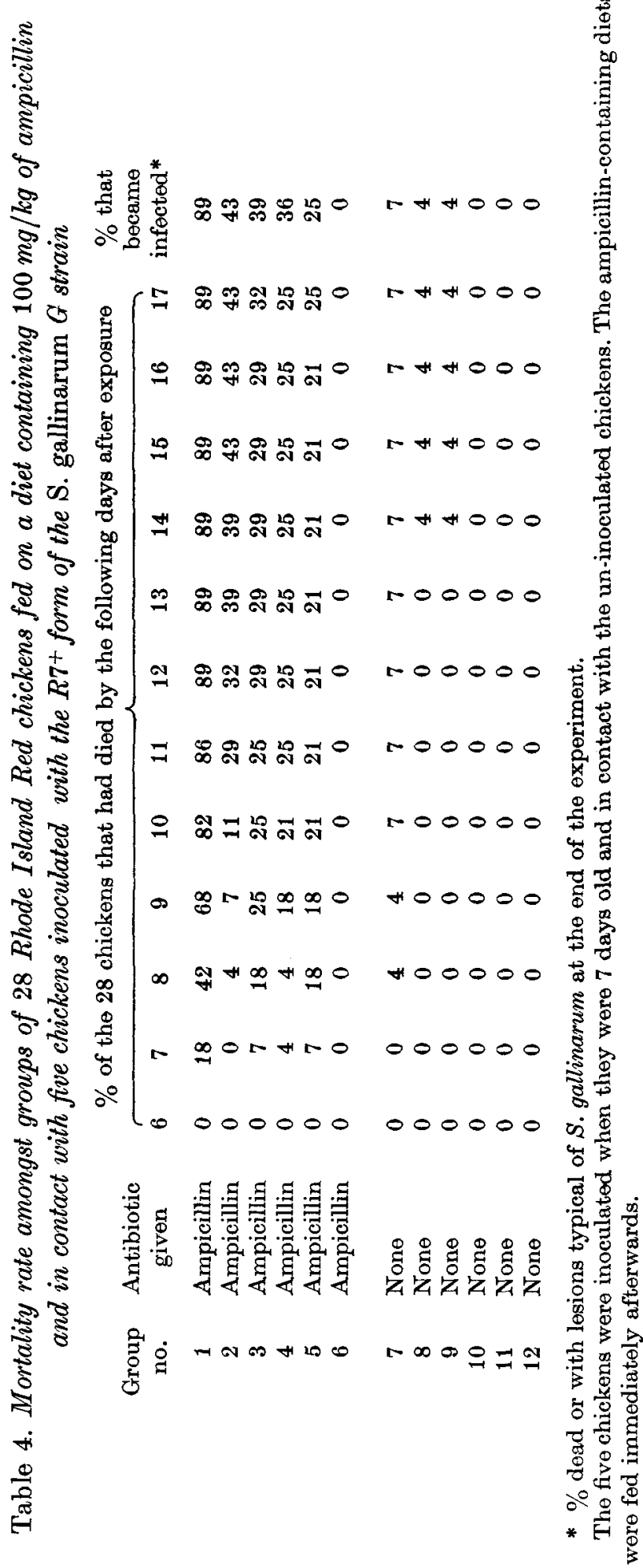


diets containing chloramphenicol or tetracycline $(100 \mathrm{mg} / \mathrm{kg})$ and, especially, streptomycin $(20 \mathrm{mg} / \mathrm{kg})$. For example, in an experiment with the $\mathrm{R5}^{+}$form the percentage of in-contact chickens whose faeces became infected in groups fed on diets containing spectinomycin, chloramphenicol, tetracyclines, streptomycin or no antibiotics was $100,96,82,11$ and 57 respectively. In two experiments with the $\mathrm{R} 1+$ form the corresponding figures were 100, 71, 82, 89 and 46 and 100, 32, 96,18 and 82 respectively. In an experiment with the $R 7+$ form the figures for groups fed on an ampicillin-containing diet and on the ordinary diet were 100 and 36 respectively. The results for the chickens exposed to $\mathrm{R5}^{+}$organisms and fed on the spectinomycin-containing diet and for the chickens exposed to the $\mathrm{R7}^{+}$ organisms and fed on the ampicillin-containing diet are shown in more detail in Table 3.

The effect of feeding a diet containing $100 \mathrm{mg} / \mathrm{kg}$ of ampicillin to groups of 28 Rhode Island Red chickens kept from hatching time in the same pen as five chickens inoculated orally with the R7+ form of the S. gallinarum G strain when 7 days old is summarized in Table 4; plasmid R7 specifies resistance to ampicillin. Deaths occurred more rapidly and more frequently in five of the six groups fed on the ampicillin-containing diet than in the six groups fed on the ordinary diet. At the end of the experiment lesions typical of $S$. gallinarum infection were found in five of the surviving chickens in the ampicillin-fed groups and in none of those fed on the ordinary diet; none of the survivors had demonstrable antibodies to S. gallinarum in their blood. When the experiment was repeated, the spread of infection was much less. The proportion of chickens that acquired infection in the ampicillin-fed groups was $22,11,4,0,0$ and $0 \%$ and in the non-medicated groups $7,4,4,4,0$ and $0 \%$. All the infections were identified by death of the host; the survivors were free of lesions and of blood agglutinins to $S$. gallinarum. In a similar experiment in which the infecting organisms were of the $\mathrm{R} 1+$ form of the $G$ strain, the proportion of chickens that became infected in each of two groups given food containing $100 \mathrm{mg} / \mathrm{kg}$ of spectinomycin, chloramphenicol or tetracycline or $20 \mathrm{mg} / \mathrm{kg}$ of streptomycin was 57 and 11,21 and 4,4 and 0 and 7 and 0 respectively. None of the chickens in two non-medicated groups became infected. This experiment was repeated twice, no spread of infection occurring on either occasion. In these repeat experiments, and in the previous experiments, a total of 12 groups of chickens were included in which the organisms inoculated were of the $\mathrm{R}^{-}$parent form of the $\mathrm{G}$ strain and in which the diet was the ordinary one; no spread of infection was detected in any of the groups.

\section{DISCUSSION}

Although the plasmids we studied had been incriminated in severe epidemics their transfer to the S. typhimurium and S. gallinarum strains was never accompanied by an increase in virulence for chickens. This was so when the $\mathrm{R}^{+}$forms of the $S$. typhimurium strain tested were from matings in which at least $10 \%$ of the recipient organisms had acquired the plasmid - such forms would be less likely to have been derived from organisms of reduced virulence that had conjugated preferentially with donor organisms (Smith, 1972; Watanabe, 1976). Usually the 
virulence of the $\mathrm{R}^{+}$forms of the $S$. typhimurium and $S$. gallinarum strains that were created was similar to or less than that of their $R^{-}$parent forms. The fact that the virulence of some of them was increased little or not at all following plasmid removal strongly suggests that they were indeed less virulent mutants of the recipient strain that had conjugated preferentially with the donor organisms. The studies on the four $\mathrm{R5}^{+}$forms of the $S$. gallinarum strain that had been obtained from different matings threw the most light on the effect of plasmid transfer on virulence. One form, $\mathrm{R5}(4)^{+}$(Table 2), was as virulent as the $\mathrm{R}^{-}$ parent strain and another, R5(1)+, was completely avirulent. Because the virulence of the latter was not increased by plasmid removal it must be regarded as an example of preferential conjugation of an avirulent mutant of the parent recipient strain. Forms R5(2)+ and R5(3)+ were in a different category. They, too, were less virulent than the $R^{-}$parent strain but after plasmid removal their virulence attained that of the parent strain. No reason was found to account for this. In in vitro conjugation studies the plasmids of all four forms transferred at the same rate and no sex pili were seen by electron microscopy in $R 5(3)^{+}$forms of the $S$. gallinarum strain or of an $E$. coli $\mathrm{K} 12$ strain. Thus it is unlikely that plasmid derepression was implicated in the reduced virulence of the R5(2) and R5(3) forms of the $S$. gallinarum strain. This phenomenon, however, was probably responsible for the decreased virulence of the de-repressed $\mathrm{F}^{+}$and $\mathrm{I}^{+}$forms of the S. typhimurium strain (Table 1) because the virulence of both these forms was restored to that of their $\mathrm{R}^{-}$parent strain by plasmid removal and because the virulence of the repressed $\mathrm{F}^{+}$form was similar to that of the $\mathrm{R}^{-}$parent form.

Even though our virulence studies provided no evidence to indicate that any of the plasmids had enhanced the virulence of their wild hosts, the extensive nature of the epidemics in which their original hosts had been incriminated inferred that they might well have enhanced their hosts' infectivity. None of our experiments in chickens designed to elucidate this hypothesis supported it. Chickens inoculated orally did not excrete organisms of the $\mathrm{R}^{+}$forms of the $S$. typhimurium strain in greater amounts or for longer periods of time than they did organisms of the $\mathbf{R}^{-}$parent form. Furthermore, in the experiments in which only five chickens in each group were inoculated there was no evidence that organisms of the $\mathrm{R}^{+}$forms of the $S$. typhimurium and $S$. gallinarum strains spread more rapidly or more extensively to in-contact chickens than organisms of the $\mathrm{R}^{-}$forms did. However, when antibiotics against which the infecting $\mathrm{R}^{+}$ organisms provided resistance were given to chickens in these experiments, the results were often quite different in that the chickens given them excreted the organisms for longer periods of time and in greater amounts and the organisms spread more rapidly and more extensively from inoculated chickens to in-contact chickens - this was well demonstrated by the high death rates observed in incontact antibiotic-fed chickens in some of the experiments with the $\mathrm{R}^{+}$forms of the $S$. gallinarum strain. It is therefore conceivable that the epidemics in which some of the plasmids had been incriminated could have been rendered even more extensive by the therapeutic and prophylactic use of antibiotics against which the plasmids provided resistance. 
We are grateful to Mrs Joan Simpson, Mrs Jill Burt and Miss Margaret Lovell for their capable technical help and to Dr P. M. Biggs, Mrs Sylvia Lewin and Miss Susan Shaw for assistance in a variety of ways.

\section{REFERENCES}

Anderson, E. S. (1968). Drug resistance in Salmonella typhimurium and its implications. British Medical Journal iii, 333-9.

Anderson, E. S. (1975). The problem and implications of chloramphenicol resistance in the typhoid bacillus. Journal of Hygiene 74, 289-99.

Butller, T., Linh, N. N., Arnold, K. \& Pollack, M. (1973). Chloramphenicol-resistant typhoid fever in Vietnam associated with $R$ factor. Lancet ii, 983-5.

Davis, J. E., Strauss, J. H. JR. \& Sinshermer, R. L. (1961). Bacteriophage MS2: another RNA phage. Science 134, 1427.

DatTa, N. \& Olarte, J. (1974). R factors in strains of Salmonella typhi and Shigella dysenteriae 1 isolated during epidemics in Mexico; classification by compatibility. Antimicrobial Agents and Chemotherapy 5, 310-17.

Hardy, K. G., Meyneli, G. G., Dowman, J. E. \& Spratt, B. G. (1973). Two major groups of colicin factors; their evolutionary significance. Molecular and General Genetics 125, 217-30.

KAY, D. (1962). The nucleic acid composition of bacteriophage $\phi$ R. Journal of General Microbiology 27, 201-7.

Lampe, R. M., Mansuwan, P. \& Duangmani, C. (1974). Chloramphenicol-resistant typhoid. Lancet i, 623-4.

Meyneld, G. G. \& Lawn, A. M. (1968). Filamentous phages specific for the I sex factor. Nature, London, 217, 1184-6.

Miles, A. A., Misra, S. S. \& IrwiN, J. O. (1938). The estimation of the bactericidal power of blood. Journal of Hygiene 38, 732-49.

MItsunashi, S. (1971). Epidemiology and geneties of R factors. Annals of the New York Academy of Sciences 182, 141-52.

Paniker, C. K. J. \& Vimala, K. N. (1972). Transferable chloramphenicol resistance in Salmonella typhi. Nature, London, 239, 109-10.

Peluffo, C. A., Irino, K. \& Mello, S. (1974). Virulence and multi-resistance to drugs of epidemic Salmonella typhimurium strains isolated in children's hospitals in South America. I. Comparative virulence of epidemic and non-epidemic strains. Memórias do Instituto Butantan 38, 1-12 (in Spanish).

Smrth, H. Williams (1955). Observations on experimental fowl typhoid. Journal of Comparative Pathology and Therapeutics 65, 37-54.

SмIтн, H. Williams (1972). The effect on virulence of transferring $\mathbf{R}$ factors to Salmonella typhimurium in vivo. Journal of Medical Microbiology 5, 451-7.

SмIтH, H. Williams (1974). Thermosensitive transfer factors in chloramphenicol-resistant strains of Salmonella typhi. Lancet ii, 281-2.

Thinle, Elizaberth H. (1970). Virulence of R-factor-bearing Salmonella typhimurium. Infection and Immunity 2, 516.

Tomoeda, M., InUzuka, M., Kubo, N. \& Nakamara, S. (1968). Effective elimination of drug resistance and sex factors in Escherichia coli by sodium dodecyl sulphate. Journal of Bacteriology 95, 1078-89.

Watanabe, M. (1976). Effect of $R$ factors on the virulence of their host bacteria: virulence for mice of Salmonella typhimurium LT-2 carrying various $\mathbf{R}$ factors from naturally occurring Shigella strains. Japanese Journal of Bacteriology 31, 397-407 (in Japanese).

Watanabe, T. (1971). Transferable antibiotic resistance in enterobacteriaceae: relationship to the problems of treatment and control of coliform enteritis. Annals of the New York Academy of Sciences 176, 371-84.

Watanabe, T. \& Watanabe, M. (1969). Episome resistance factors in Enterobacteriaceae: 38. Virulence for mice of Salmonella typhimurium LT-2 carrying various $\mathbf{R}$ factors: Igaku to Seibutsugaku 79, 139-47 (in Japanese). 